\title{
O ensino de inglês por meio de tecnologias digitais como complemento das aulas presenciais do ensino fundamental
}

\author{
Teaching English Through Digital Technologies as a Complement to Face-to-Face \\ Elementary School Classes
}

Daiane Massucatto (iD https://orcid.org/0000-0002-4474-5878

Universidade Estadual de Maringá

e-mail - aeronani81@gmail.com

Luizete Guimarães Barros (iD https://orcid.org/0000-0002-8618-2591

Universidade Estadual de Maringá

e-mail - luizetebarros@yahoo.com.br

\section{Resumo}

Esta pesquisa tem como objetivo elaborar uma proposta didática de ensino híbrido para estudantes em contato inicial com o estudo de inglês como língua estrangeira. Baseado na dificuldade da escola pública brasileira em adaptar-se às necessidades da sociedade do século XXI e classificar-se, segundo os parâmetros de Lengel (2012), na educação 3.0, surge nosso interesse em propor uma experiência didática que utiliza as novas tecnologias. A partir da necessidade do desenvolvimento da oralidade no ensino de inglês, propõem-se atividades utilizando o WhatsApp, cujo conteúdo é a saudação inicial em uma conversação. Apesar da indicação como complemento das aulas presenciais, tais atividades fazem parte do componente curricular da sexta série do Ensino Fundamental II, conforme indicado pelo material didático utilizado nesta pesquisa.

Palavras-chave: Ensino de Línguas. Recursos Tecnológicos. Segundo Ciclo do Ensino Fundamental.

\begin{abstract}
This research has as its objective the elaboration of a didactic proposition of hybrid teaching for students having an initial contact with the study of English as a foreign language. Based on the difficulty of the public school system in Brazil to adapt to the needs of twenty-first century society and classify itself, according to the parameters of Lengel (2012) into education 3.0, our interest arises in proposing a didactic experience utilizing the new technologies. From the need for the development of orality in the teaching of English, activities are proposed using WhatsApp, the content being an initial greeting in a conversation. Despite the indication as an
\end{abstract}


addition to on-site classes, these activities are part of the curricular component of the sixth grade of Ensino Fundamental II (middle school), as indicated by the didactic material used in this research.

Keywords: Language Teaching. Technological Resources. Second cycle of Elementary School

\section{Introdução}

O avanço das tecnologias e a crescente propagação da internet têm modificado consideravelmente a vida das pessoas na sociedade do mundo todo, de forma a alterar e facilitar uma série de serviços como compras e/ou reservas on-line, correios eletrônicos, pesquisas de todo o tipo, redes sociais, etc. Por muito tempo se viveu sem nenhum desses recursos de informática, porém, a vontade de tornar mais práticas certas atividades, ou mesmo a comunicação humana, fez com que o homem usasse suas habilidades para criar tais acessórios.

Segundo Carvalho (1997, p.73), "as inovações tecnológicas derivam basicamente do capitalismo, que surgiu como um novo modelo de produção entre os séculos XVIII e XIX, refletindo em uma nova sociedade, uma sociedade tecnológica".

Com o passar do tempo, as tecnologias foram evoluindo e ganhando espaço também nas salas de aula, onde cada vez mais podemos encontrar notebooks, tablets e até smartphones, pois são recursos que enriquecem o estudo, e facilitam o acesso a um conteúdo diversificado, assim como auxiliam na interação e na comunicação. Jovens e adolescentes estão tão versados no uso das novas tecnologias que elas se incorporaram às atividades da sociedade do século XXI, não só na esfera da diversão e do entretenimento, como também na esfera da pesquisa e do conhecimento. Portanto, utilizar recursos tecnológicos em sala de aula serve como elemento de motivação ao alunado, e o trabalho com essas tecnologias além do horário escolar pode potencializar seu uso, atualizando as ferramentas didáticas empregadas na escola, e transformando o modo como aprendemos.

Para a UNESCO (2014 p.7), “as tecnologias móveis podem ampliar e enriquecer oportunidades educacionais para estudantes em diversos ambientes". Mas para isso é necessário que o professor esteja preparado e tenha contato constante com as ferramentas que pretende utilizar como complemento de suas aulas, pois ao contrário seria considerado um analfabeto digital, que, de acordo com Menezes e Santos (2001, p. 1), "refere-se a uma incapacidade em 'ler' o mundo digital e mexer com a tecnologia moderna".

Um professor apto pode ser mediador no processo de ensino e aprendizagem e colaborar para com a preparação de seus alunos para serem cidadãos atuantes em uma sociedade informatizada. Por esta razão, o objetivo desta pesquisa é elaborar uma proposta didática de ensino híbrido para estudantes brasileiros em primeiro contato com a língua inglesa. Para tanto, examinam-se modelos de prática pedagógica que utilizam as Tecnologias da Informação e Comunicação (TIC) no sentido de conhecer os modelos existentes e optar pelo emprego do WhatsApp como recurso didático facilitador da comunicação oral entre alunos. 
Priorizamos, portanto, a prática oral que justifica a escolha das mensagens de áudio via WhatsApp como atividade inicial para alunos do Ensino Fundamental. Outra justificativa desta pesquisa é o fato de que as novas tecnologias não devem se distanciar do espaço escolar, muito menos as inovações mais recentes que já caíram no domínio público dos adolescentes que compõem o corpo discente em questão. Por essa razão, este artigo pretende mostrar como as atividades complementares mediadas pelas mídias digitais podem contribuir para um processo de ensino e aprendizagem de língua inglesa significativo.

\section{Procedimentos metodológicos}

Para o desenvolvimento deste trabalho, a metodologia utilizada foi a revisão bibliográfica, no intuito de reunir conhecimentos sobre as áreas de ensino de línguas e sobre a evolução da utilização das tecnologias na educação. Empregando o método de pesquisa qualitativa, que não se vale de números ou estatísticas, mas se baseia na leitura de referencial teórico, concordamos com os autores Kauark, Manhães e Medeiros (2010) que afirmam, em corroboração a Neves (1996), que este tipo de pesquisa não busca enumerar ou medir eventos, nem emprega instrumental numérico para análise de dados; seu foco de interesse é amplo e parte de uma pesquisa diferenciada da adotada pelos métodos quantitativos.

Assim, a coleta de dados foi realizada por meio de pesquisa em livros, artigos publicados na internet, entre outros. Há informações detalhadas e análise de parte do primeiro capítulo do livro Way to English for Brazilian Learners - do $6^{\circ}$ ano do Ensino Fundamental (FRANCO; TAVARES, 2017), bem como do aplicativo WhatsApp, e de documentos sobre o assunto. Logo, este artigo consiste em fazer uma reflexão do uso das Tecnologias digitais da Informação e Comunicação (TIC) como um meio de colocar em prática conteúdos vistos em sala, como atividade curricular ou extracurricular.

\section{Educação 3.0}

Teixeira e Ferreira (2017) são professores de língua espanhola que compartem a visão da precariedade do ensino das línguas estrangeiras nas escolas públicas do Brasil. Os motivos dessa insatisfação se devem, em certa medida, às turmas geralmente numerosas, com mais de trinta alunos, e à carga horária reduzida. Essa realidade se mostra um desafio para o professor de línguas estrangeiras, em geral, e de inglês, em particular, que reconhece a dificuldade de praticar, de forma escrita ou oral, os conteúdos veiculados em classe. Soma-se a esses fatos o agravante de que, muitas vezes, o professor não é fluente na língua que ensina e fica preso exclusivamente ao livro didático, sem encontrar maneiras de atender os anseios dos alunos. Jalil e Procailo (2009) tecem comentário pertinente sobre o papel assumido pelo professor na escola formal em que vigorava, quase que exclusivamente, a aula expositiva. Eles dizem:

O professor-transmissor, neste escopo, colocava-se como a peça central da sala, pois detinha o saber, e pouca iniciativa era atribuída aos alunos. Sendo a autoridade em sala de aula, o professor corrigia os alunos para que sempre obtivessem a resposta correta. Portanto, ambos assumem uma postura tradicional, uma vez que o professor é o detentor do saber e o aluno é um mero aprendiz que realiza as atividades exatamente 
conforme orientado. Além disso, a interação acontece sempre do professor para o aluno. (JALIL; PROCAILO. 2009, p. 3)

Ainda que esse texto conjugue no passado a atitude do professor-transmissor, tal prática persiste nos dias atuais. $E$ ainda que o século $X X$ tenha proporcionado grande contribuição ao ensino-aprendizagem de idiomas pela criação de diferentes métodos - audiolingual, comunicativo, entre outros.-, o século XXI apresenta um desafio ao professor ao colocá-lo como mediador de uma aprendizagem que, como já se sabe, se vale de diferentes estratégias por contar com alunos com diferentes dificuldades e com diferentes aptidões e habilidades. O percurso do ensino de idiomas, que tem nos seus primórdios o método gramática-tradução, passa pela proliferação de métodos no século $X X$, culminando com a era do pós-método, em que o professor assume papel de mediador, no século atual.

Dada essa sucinta evolução metodológica em lingüística aplicada, resolvemos adotar outra ótica para tratar, em linhas gerais, do quadro evolutivo da educação. $E$ para se ter um percurso do modelo de ensino através dos tempos, recorremos a Coelho (2016) que traça um histórico da educação ao longo dos séculos, e reconhece que o modelo de professor que a sociedade demanda hoje deve ser condizente com as necessidades atuais. No século XIX, segundo Lengel (2012 apud COELHO, 2016), figurava o modelo de educação 1.0, onde o professor era o detentor de todo o conhecimento e o transmitia para poucos ou mesmo para um único aluno, e isso era reservado para uma minoria considerada nobre, intelectual ou de filósofos.

Esse tipo de educação do século $\mathrm{XIX}$ persiste no século $\mathrm{XX}$, naquilo que Lengel (2012) chama de educação 2.0, pelo fato de que o professor continua a desempenhar o papel principal de detentor do conhecimento. A diferença entre esses dois séculos se explica porque o público muda, isto é, o professor se dirige a um número bem maior de pessoas, razão pela qual se faz necessária a padronização e a sistematização do ensino, que, em certa medida, vigora até hoje. Esse padrão educativo é chamado por Lengel (2012) de educação 2.0.

No século $X X I$, no entanto, para atender a grande maioria das pessoas surge a educação 3.0. O advento da internet e o surgimento de novas gerações em plena era digital impõe novas necessidades pedagógicas, isto é, outras formas de ensinar e de aprender, assim como aplicativos de acesso fácil a toda população. Para tanto, passa-se a repensar o papel do professor, que tem outras características dentro da educação 3.0, fazendo dele também um professor 3.0. Segundo Lengel (2012 apud COELHO, 2016, p. $39-40)$ :

A Educação 3.0 desenvolve as competências necessárias para o mundo moderno de pesquisa e trabalho: curiosidade, pensamento rápido, busca de ideias, trabalhar em grupo colaborativo, integrar ideias de várias disciplinas, e uma compreensão das ideias principais que explicam a condição humana e o progresso.

Ainda de acordo com Lengel, o professor passa a ser um mediador e não o detentor do conhecimento, pois o ensino se centraliza no aluno, o verdadeiro protagonista no processo de ensino e aprendizagem. Quanto a isso, Coelho (2016, p. 53) parece concordar quando diz que:

A redefinição de papéis demanda que o profissional deixe de ser apenas o transmissor das informações e passe a ser o facilitador, colaborador, problematizador, mediador de práticas inovadoras que envolvem novos procedimentos e atitudes, direcionadas a motivar a conexão entre os 
objetivos e os alunos, num desafio constante de consolidar um ensino de qualidade. (COELHO, 2016, p. 53).

No entanto, não basta saber manusear as ferramentas tecnológicas, mas sim saber manuseá-las para os fins educacionais. E isto significa que elas devem ser usadas de modo contextualizado. É necessário ainda reflexão e discernimento para explorar as TIC de maneira racional e eficaz, e este é o desafio para os professores. Para tanto, enumeramos, a seguir, de maneira resumida, algumas propostas para se implantar nas aulas de língua inglesa e potencializar o ensino tecnológico, para, na sequência, expor a nossa proposta de ensino via WhatsApp.

\section{Modelo de Ensino Híbrido}

À medida que as tecnologias foram avançando, o comportamento de cada geração também foi se modificando e não poderia ser diferente na área da educação. $A$ internet ganhou um espaço bastante significativo também no ensino de idiomas, a exemplo dos inúmeros cursos on-line ofertados atualmente. Cada vez mais aplicativos - como Facebook, SMS, Skype, Youtube, WhatsApp -, com objetivos pedagógicos diversos têm sido usados em sala de aula e até mesmo fora dela, conforme atestam os estudos de Costa e Lopes (2015) e Prensky (2010), entre outros. Esse novo jeito de ensinar, onde há aula presencial e também extraclasse por meio das mídias digitais, é conhecido como hibridismo, ou blended learning. De acordo com Christensen; Horn; Stalker (2013, p.42 apud COELHO, 2016, p. 53):

O modelo híbrido incorpora as principais características e vantagens do ensino on-line combinadas com os benefícios da sala de aula tradicional, permitindo que os estudantes aprendam virtualmente ao mesmo tempo que se beneficiam da supervisão física e, em muitos casos, da instrução presencial.

Segundo Christensen; Horn; Staker (2013, p. 3 apud Coelho 2016, p. 43), há alguns modelos de ensino híbrido, porém os mais conhecidos são seis, a saber: Rotacional, Laboratório Rotacional, Sala de Aula Invertida, Flex, à la carte e Modelo Virtual Enriquecido.

No Modelo Rotacional, um grupo de alunos passa por estações para a realização de tarefas em sala de aula e vão trocando, fazendo rotações, sendo que uma das estações é destinada ao uso de plataforma digital.

Há também o Laboratório Rotacional, no qual os alunos passam um determinado tempo na sala de aula e em seguida vão para um laboratório para desenvolver atividades on-line.

Já no Modelo Sala de Aula Invertida, os estudantes têm primeiro contato com conteúdo por meio de tecnologias digitais fora da escola e a parte prática acontece posteriormente na escola, onde se discute a teoria e/ou se realiza outra tarefa.

No Modelo Flex, que tem como base o ensino on-line, embora o professor atenda presencialmente, conforme a necessidade de apoio e instrução, a rotina é individual e personalizada, já que cada aluno tem seu próprio ritmo e um planejamento, sendo possíveis horários fluidos entre uma atividade e outra.

No Modelo à la Carte, por sua vez, os alunos podem se inscrever em um ou mais cursos inteiramente on-line, ao mesmo tempo que têm aulas presenciais em escola tradicional. 
E, por fim, no Modelo Virtual Enriquecido, o aluno, na maior parte do tempo, acessa conteúdos e tarefas on-line em casa e outra parte do tempo frequenta uma escola física, com professores presenciais, mas sem a obrigatoriedade diária.

Partindo da concepção de que no ensino híbrido "o estudante mescla oportunidades virtuais e reais de aprendizagem, num processo contínuo entre o encontro físico e o digital" (COELHO, 2016, p. 25), na próxima seção propõe-se demonstrar de que forma se pode aplicar as atividades complementares por meio do aplicativo de WhatsApp para desenvolver a oralidade em alunos $6^{\circ}$ ano do Ensino Fundamental II.

\title{
Atividades práticas por meio do WhatsApp
}

Conforme Bottentuit Júnior (2012, p. 131):

\begin{abstract}
Grande parte dos alunos já possuem aparelhos celulares e a grande maioria também possui equipamentos modernos (smartphones) que além de fazer e receber chamadas e mensagens funcionam como verdadeiros computadores portáteis, permitindo ainda acesso à Internet e, também, a uma gama muito variada de aplicativos.
\end{abstract}

Partindo do pressuposto acima, optamos por trabalhar com o WhatsApp como a ferramenta tecnológica que contribui no processo de ensino e aprendizagem complementar às aulas de Língua Inglesa, por ser um aplicativo gratuito muito popular e que pode de ser baixado em celulares com diferentes sistemas operacionais, como Android e IOS, por exemplo. Neste, é possível enviar fotos, vídeos, links e ainda mandar mensagens escritas ou gravadas em áudio, para interação individual ou coletiva.

Como descrição dessas atividades práticas, alertamos que essa pesquisa é feita por uma professora de inglês com poucos anos de experiência em sala de aula. Como planejamento desta proposta didática, sugerimos a criação de um grupo chamado Speak Up - 6th Grade, no qual os números de telefone dos alunos são inseridos para que todos possam receber as atividades por meio do aplicativo e interagir com o professor, cujo papel é mediar todo o processo, e atuar também o administrador do grupo. Esse papel do professor é reconhecido por Coelho (2016, p.148) quando diz que:

Não podemos deixar de mencionar que o recurso também contribui para o trabalho do professor, no sentido de monitorar o acesso dos alunos, bem como facilitar a elaboração, postagem e avaliação das atividades propostas. Com isso o professor passa a assumir o papel de mediador, de orientador e pode estimular as interações on-line. (COELHO, 2016, p. 148).

Nessa proposta, sugerimos introduzir o assunto por meio de uma aula explicativa, em que os alunos levem à aula seus aparelhos celulares para que compreendam, na prática, como tudo funciona, podendo-se explorar os recursos do aplicativo em questão para se certificar que todos conseguem manuseá-lo. Em caso de algum aluno não possuir um dispositivo móvel, pode-se seguir a sugestão de Bento e Cavalcante (2013, p. 119):

Propor atividades em dupla ou até mesmo coletivas seria uma boa ideia para amenizar essas situações, além de proporcionar uma discussão com

Revista de Estudos e Pesquisas sobre Ensino Tecnológico, v. 6, e93220, 2020. 
opiniões diversificadas e preparando para que eles possam trabalhar em equipe sabendo respeitar as ideias contrárias. (BENTO; CAVALCANTE, 2013, p. 119).

A partir da criação do grupo, aconselhamos que seja examinado o material didático que trata sobre o tema escolhido para esta pesquisa, a saber: saudações e cumprimentos. Este assunto compõe a primeira unidade do livro-texto da disciplina de Língua Inglesa do sexto ano do Ensino fundamental, adotado em grande parte das escolas públicas da região norte do estado do Paraná, em geral, e da cidade de Maringá, em particular: cidade em que foi desenvolvida essa pesquisa. A coleção Way to English for Brazilian Learners, publicada, em sua primeira edição de 2017, pela editora Ática, de autoria de Claudio Franco e Katia Tavares, faz parte das obras selecionadas pelo Programa Nacional do Livro e do Material Didático (PNLD).

Além de ter este selo de qualidade concedido pelo Ministério de Educação e Cultura - MEC -, esta obra tem como objetivo criar cidadãos críticos em língua inglesa, e se vale do uso da linguagem para as práticas sociais, assim como preconiza a Base Nacional Comum Curricular (BNCC). Essas são algumas das justificativas da nossa opção por este material didático.

E para cumprir o objetivo de usar a linguagem nas práticas sociais, um dos objetivos propostos pela primeira unidade são: aprender como cumprimentar e apresentar pessoas. Na seção Warming Up da Unidade 1, páginas 18 e 19, os autores Franco e Tavares (2017, p. 18) apresentam a ilustração de várias crianças sinalizando um cumprimento com a mão e as perguntas que visam ativar o conhecimento prévio dos alunos: "Como você costuma cumprimentar seus amigos? E sua família? E seus professores? Você já usou expressões em inglês para cumprimentar alguém? Em caso afirmativo, quais?".

Na página seguinte são apresentadas atividades com perguntas de pré-leitura, para motivar e introduzir o tema que será tratado no texto, que é uma tirinha, ou comic strip, em inglês, e isso acontece na atividade de Before Reading, que contém três exercícios com perguntas abertas e questões objetivas. Na sequência vem a atividade de leitura, ou Reading, onde na tirinha intitulada Classic Peanuts, conforme Figura 1, o personagem Snoopy está sendo cumprimentado por outros personagens que passam por ele. Os exercícios seguintes são voltados para a compreensão geral e mais detalhada do texto, nas atividades de 1 a 4 . Já a atividade 5 , na página 22, busca promover a reflexão crítica, levando os alunos estabelecerem uma relação entre o texto e sua realidade, como exposto na Figura 1. 
Figura 1 - Atividade de Leitura, Reading - Classic Peanuts

\section{Reading}

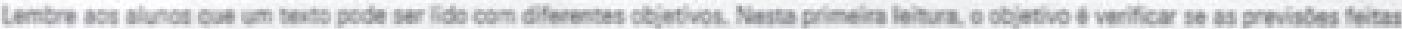
Now read the text below to check your predictions.
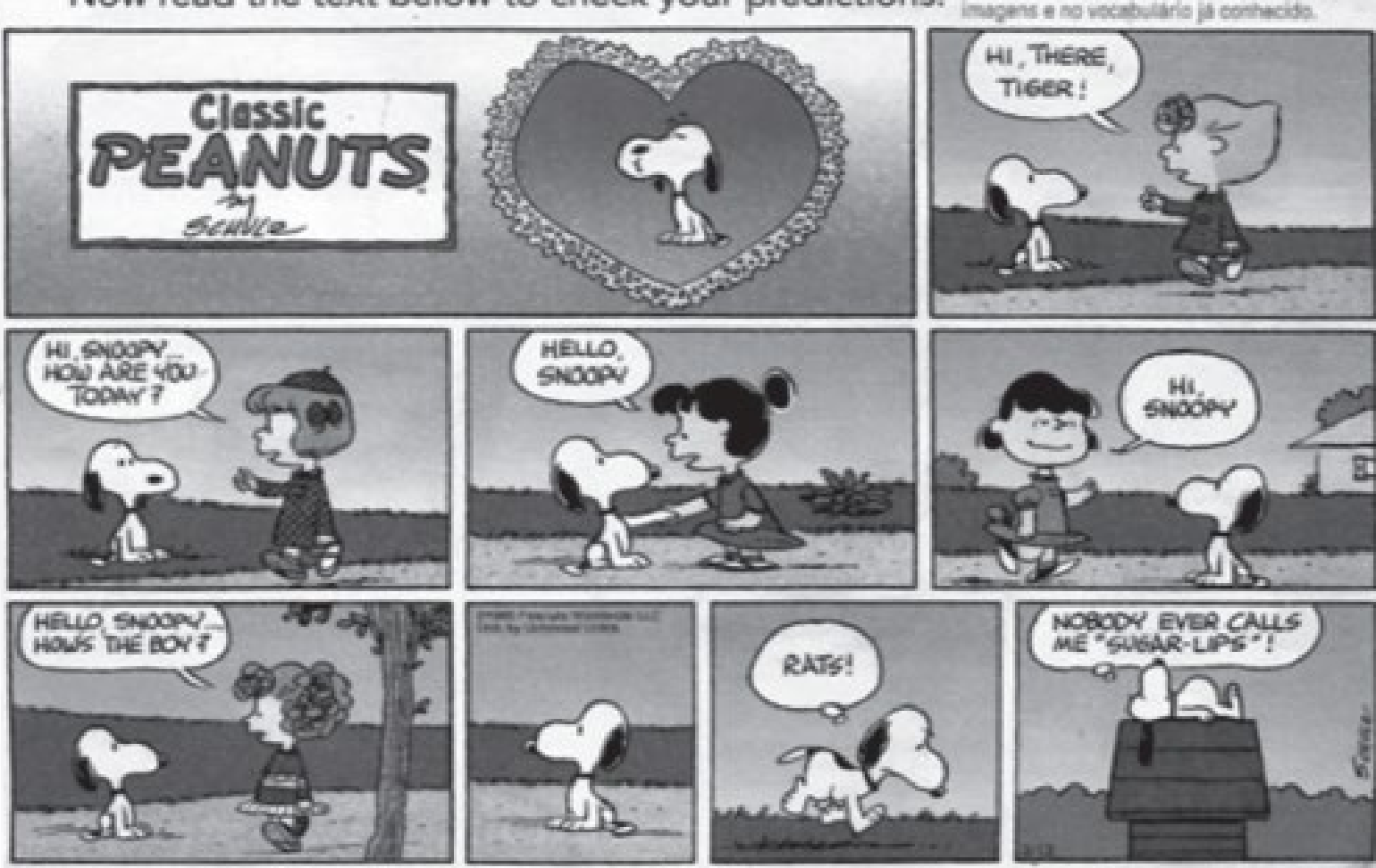

SCHULZ, Charles. Classic Peanuts. Avallable at: <www.peanuts.com>. Accessed in: July 2014

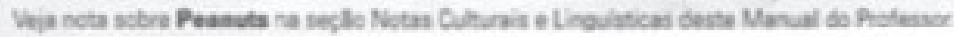

Match the columns below.
a. Charles Schulz
b. Peanuts
C. Snoopy

b) is the name of the comic strip.

c5 is the name of the dog.

(a) is the name of the creator of the comic strip.

2 Complete the following sentences. Use the expressions from the box below.

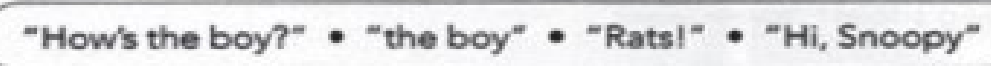

a. "Hello, Snoopy" is equivalent to $\mathrm{xs}$ shoed

b. "How are you today?" is equivalent to Nems mebor"

c. "Tiger" and mober refer to "Snoopy".

1. The exclamation nasi expresses irritation.

3 Match the columns below.

a. Como Snoopy é chamado por uma das meninas?

b. Como Snoopy gostaria de ser chamado?

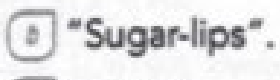

(4) "Tiger".

Fonte: FRANCO; TAVARES (2017, p. 21) 
Na seção Vocabulary Study (Figura 2), são apresentados dois diálogos retirados dos dois primeiros quadrinhos da tirinha Classic Peanuts, no qual aparecem duas formas de cumprimentar alguém, no caso, o personagem Snoopy: "Hi, there, Tiger", dito pela personagem Sally e "Hi, Snoopy... How are you today?", dito por outra personagem. No primeiro momento os alunos devem completar o diálogo com as frases no box: "I'm fine, thanks" e "Hello, Sally"; e a atividade seguinte é a prática do diálogo em pares, usando seus próprios nomes e invertendo os diálogos, oferecendo assim oportunidades de praticar a pronúncia de palavras e expressões.

Figura 2 -Vocabulary Study - Classic Peanuts

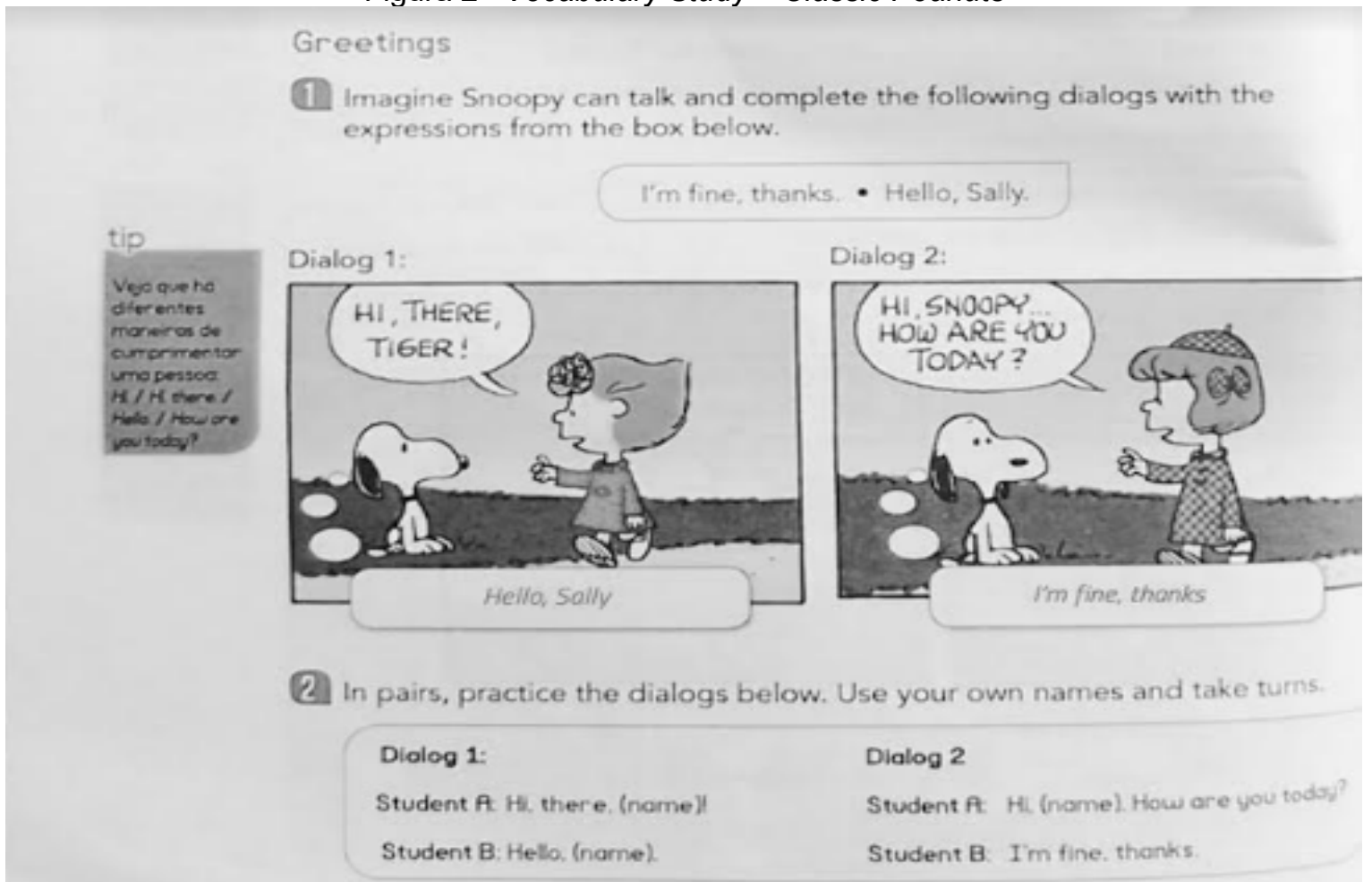

Fonte:Way to English - for Brazilian Learners (2017)

Propõe-se, conforme o conteúdo exposto acima, sugerir algumas atividades relacionadas a "Cumprimentos" para alunos do $6^{\circ}$ ano do Ensino Fundamental por meio do aplicativo WhatsApp, porém agregando outros aplicativos em caso de necessidade, como o Google Tradutor e o YouTube, por exemplo, tendo em vista que este processo de ensino e aprendizagem de Língua Inglesa pode se tornar mais atraente e prazeroso, como destacam Moran, Massetto e Beherens (2014, p. 31 apud FELICIANO, 2016, p. 3) ao dizer que:

Com isso é possível pesquisar de todas as formas, utilizando todas as mídias, todas as fontes, todas as maneiras de interação. Pesquisar às vezes todos juntos, ou em pequenos grupos, ou mesmo individualmente. Pesquisar na escola ou em diversos espaços e tempos. Combinar pesquisa presencial e virtual. Relacionar os resultados, compará-los, contextualizá-los, aprofundá-los, sintetizá-los. O conteúdo pode ser disponibilizado digitalmente.

Após a criação do grupo Speak up! 6th Grade no aplicativo de WhatsApp, o professor deve se apresentar por meio do mesmo, conforme a figura 3 , e em seguida postar a atividade, que no caso será composta por link de um vídeo do 
YouTube, que pode ser assistido neste mesmo local, ou seja, sem precisar ser direcionado para o YouTube. O título do vídeo é Greetings and Goodbyes Saudações e Despedidas", disponibilizado no link: https://www.youtube.com/watch?v=uBA90FUG-Ko\&t=163s, tem duração de cerca de cinco minutos, ensina alguns cumprimentos básicos de acordo com diferentes períodos do dia e apresenta também algumas formas de se despedir de alguém.

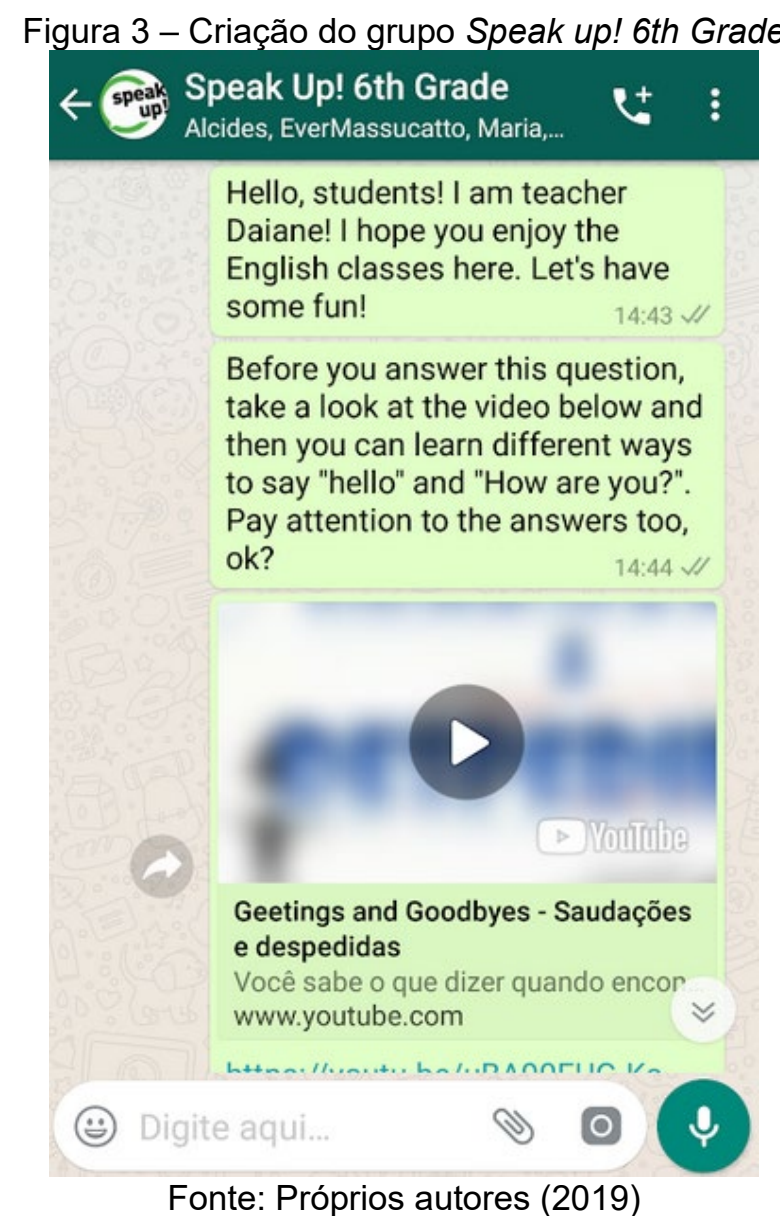

O administrador do grupo deve postar em seguida as instruções, de preferência por escrito e em língua inglesa, pedindo para que os alunos assistam ao vídeo, e que façam, depois, uma pesquisa sobre os diferentes tipos de cumprimento e escolham um para dizer por áudio a ser gravado, citando o nome de um colega, que deve responder e em seguida fazer o mesmo dizendo o nome de outro colega e assim sucessivamente. A ideia é que os alunos ouçam os áudios dos seus colegas e assim possam praticar o Listening (Ouvindo) e o Speaking (Falando), aprendendo de forma coletiva e prazerosa, como está ilustrado na Figura 4. 
Figura 4 - Exemplo de atividade

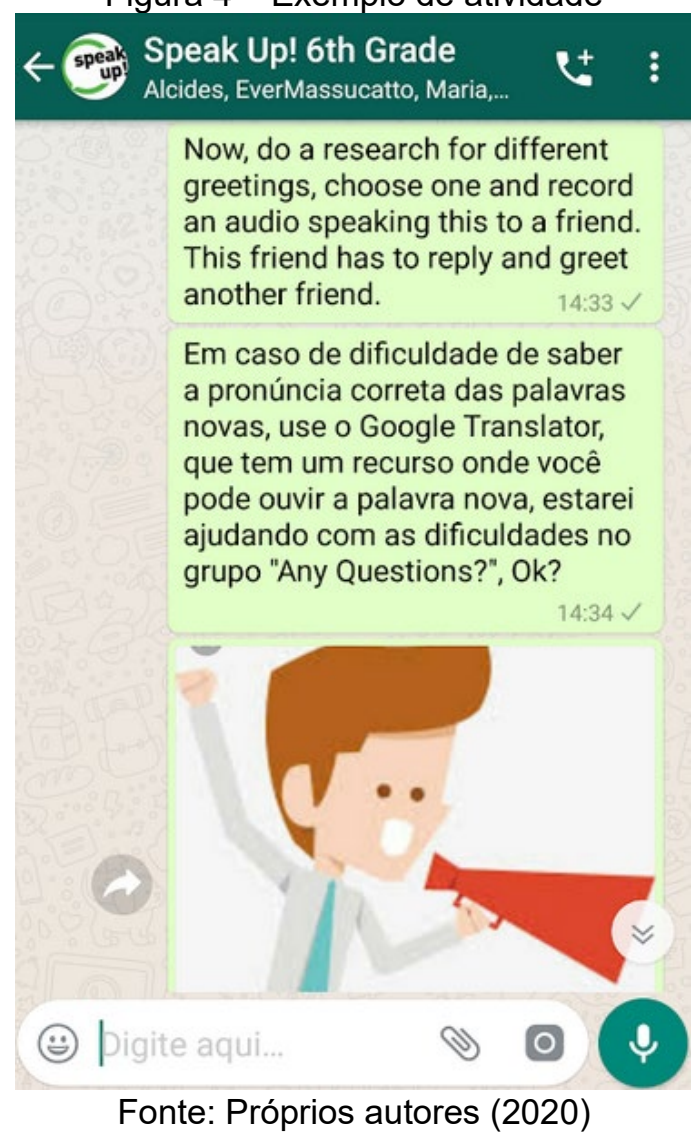

Outra sugestão é que se crie um grupo à parte, que podemos intitular Any Questions? apenas para tirar dúvidas, seja de pronúncia, escrita, ou relacionada à técnica de manuseio do aplicativo, etc, o que pode ser feito na língua que o aluno se sentir mais à vontade, levando em consideração que se trata de alunos iniciantes.

No caso de apenas alguns alunos gravarem áudio e ocorrer uma pausa muito longa até que o próximo grave, o professor pode intervir e movimentar o grupo, cumprimentando mais alguém que ainda não foi citado.

Ao longo da atividade, o professor pode ir anotando as palavras que os alunos tiveram mais dificuldade de pronunciar, escrevê-las e repeti-las em áudio gravado, sem citar nomes, apenas para mostrar a forma correta e ajudar a memorizá-la na pronúncia apropriada. E assim, de acordo com Costa (2011), o professor vai aproveitando as potencialidades do celular como um importante recurso pedagógico, tendo em vista que essa tecnologia está presente na vida de todos os alunos.

Uma recomendação adicional ao grupo de WhatsApp é o trabalho com música. E para desenvolver uma atividade desse tipo nos inspiramos em Murphey (1996, p.6 apud BRITTO, 2012, p. 4), que diz:

As canções podem ser imensamente valiosas para o desenvolvimento de certas capacidades e ao explorá-las criativamente se faz a ponte entre a experiência prazerosa de ouvir/cantar e o uso comunicativo da linguagem."

Sendo assim, o professor/administrador pode postar um link do YouTube com o vídeo "Greetings song", com letra e música de André Luiz Raphael, disponível em: https://www.youtube.com/watch?v=ijvYOKr7vUQ que contém, além de formas 
extras, muitas das formas de cumprimentar alguém, já conhecidas pelos alunos por meio das unidades trabalhadas anteriormente. Os alunos devem ouvir os cumprimentos e suas respectivas respostas, prestar atenção à pronúncia das palavras, num primeiro momento e depois, o professor pode postar a letra para que vejam a forma escrita. Uma das frases, What's up? contém uma resposta errada: "Very well", entretanto os alunos podem tentar identificá-la, a pedido do professor, realizando uma pesquisa, se necessário. Posteriormente, podem combinar de cantarem a música juntos, num momento presencial.

Enfim, estas são algumas sugestões de atividades para trabalhar com iniciantes do $6^{\circ}$ ano do Ensino Fundamental II. À medida que o estudo das unidades do livro didático for avançando, os desafios podem ir aumentando e o aplicativo de WhatsApp pode também ser explorado como ferramenta de uso pedagógico.

A criatividade do professor proporcionará outras propostas de diálogos e conversas em inglês entre os alunos, e caso necessite de apoio para a complementação de idéias neste particular, sugerimos a leitura de artigos, tais como os de Senfonte e Talavera (2018), Santos (2018) e Zardini (2016), que trazem o tema do uso do WhatsApp em aulas de inglês. A dissertação de mestrado de Martins (2017) é um dos exemplos de pesquisa de pós-graduação produzida sobre este assunto.

Outras línguas estrangeiras já apresentam também trabalhos sobre este tema, como, por exemplo, em espanhol destacam-se os estudos de Coelho, e, além dos já citados, há o de Coelho e Pinheiro (2017), com propostas de diálogos que complementam as ideias de comunicação oral.

\section{Considerações finais}

Utilizar o aplicativo de WhatsApp como ferramenta pedagógica para complementar o conteúdo das aulas presenciais da disciplina de Língua Inglesa do $6^{\circ}$ ano do Ensino Fundamental II pode ser um desafio. Pode ser que os alunos desta faixa etária estejam entrando em contato pela primeira vez com o ensino de uma língua estrangeira e, ainda, corre-se o risco de estarem imaturos digitalmente, embora isso possa ser facilmente corrigido pela ajuda de colegas ou de outros professores.

A presente proposta visa desenvolver a oralidade de alunos em estágio inicial no aprendizado de inglês, e versa sobre o primeiro contato social, isto é, o cumprimento que serve como introdução a um bate-papo informal. Para tanto, é sugestiva a citação de Costa e Lopes (2015, p. 48) que explicam o termo WhatsApp com as seguintes palavras:

\footnotetext{
Destacamos o próprio nome do aplicativo, o qual nos remete à expressão de língua inglesa “What's up?", utilizada tanto para perguntar a alguém se há algo de errado ou, simplesmente, para saudar a pessoa como um "oi". Pontuamos que o próprio trocadilho proporcionado pelo nome da ferramenta sugere algo mais lúdico, leve e convidativo, com destaque para o público mais jovem.
}

A proposta do trocadilho de que a saudação entre os jovens americanos "What 's up?", cujo significado pode traduzir-se em português em "oi" ou "como vai?", se transforma no nome do aplicativo, e sugere, segundo os autores, um conteúdo leve 
de uma conversa entre amigos, que pode se tornar o estudo de inglês mediado pelo WhatsApp. Com esse ar descontraído, acreditamos que os estudantes brasileiros possam se familiarizar com textos orais e escritos em língua estrangeira.

O contato inicial é tema desta proposta que visa desenvolver a oralidade. E à medida que os alunos vão se aclimatando a este novo modo de aprender, o processo vai se tornando cada vez mais prazeroso e eficaz, uma vez que a carga horária presencial de ensino nas escolas é pequena para que se desenvolva bem todas as habilidades que necessitam ser trabalhadas, como writing (escrita), reading (leitura), listening (audição) e speaking (fala).

Geralmente há uma frustração, principalmente com a habilidade oral, e o WhatsApp é uma ferramenta útil para explorar este quesito, embora as demais habilidades, como escrita, também possam ser trabalhadas.

Sendo assim, este trabalho sugere o uso do WhatsApp como ferramenta para o ensino de atividades de comunicação oral que, bem utilizada, pode contribuir para com uma aquisição efetiva dos conteúdos de Língua Inglesa, pois, vivemos em uma era digital e é natural que a educação ocorra por meio dela. Desta forma, o telefone celular que o estudante se serve para a comunicação frequente entre seus pares, se mostra útil também como ferramenta de apoio na aprendizagem de língua inglesa.

\section{Referências}

BENTO, M. C. M.; CAVALCANTE, R. dos S. Tecnologias móveis em educação: o uso do celular na sala de aula. ECCOM, v.4, n. 7, p.113-120. jan/jun 2013.

BOTTENTUIT JUNIOR, J. B. Do computador ao tablet: Vantagens pedagógicas na utilização de dispositivos móveis na educação. Revista Educação Online. Vol 6, n. 1. jan - abril 2012.

BRITTO, R. L. O Professor PDE e os desafios da escola pública paranaense. Produção Didático Pedagógica. A música como instrumento no processo de aquisição de língua inglesa: uma abordagem possível? v. 2, Curitiba, 2012.

CARVALHO, M. G. Tecnologia, Desenvolvimento Social e Educação Tecnológica. Educação e tecnologia, Curitiba, CEFET-PR, v. 1, n. 1, p. 70-87, 1997.

COELHO, I. M. W. da S. (Org.). Inovação e tecnologia - caminhos para o ensino de línguas adicionais. Curitiba: Editora CRV, 2016.

COELHO, I. M. W. da S.; PINHEIRO, M. L. O. As contribuições do WhatsApp no ensino do espanhol: uma perspectiva de aprendizagem significativa. RIALE Revista Ibero-Americana de Estudos em Educação. v. 12, n. esp. 2, p. 1278 1312, ago/2017. Disponível em:

https://dialnet.unirioja.es/descarga/articulo/6202998.pdf. Acesso em: 2 jul. 2020.

COSTA, I. Novas Tecnologias. Desafios e perspectivas na educação. $1^{\circ} \mathrm{Ed}$. Clube dos Autores, 2011.

COSTA, D. M; LOPES, J. R. A perspectiva docente quanto ao uso do WhatsApp como ferramenta adicional ao ensino de inglês: um experimento em um curso livre de idiomas.XIX Congresso Nacional de Linguística e Filologia. Línguas estrangeiras

4


e tradução. Rio de Janeiro: Cadernos do CNLF, vol. XIX, no 01 - Línguas Clássicas, Textos Clássicos, p. 43-54, 2015. Disponível em:

http://www.filologia.org.br/xix_cnlf/cnlf/10/004.pdf . Acesso em: 2 jul. 2020.

FELICIANO, L. A. dos Santos. O uso do whatsapp como ferramenta pedagógica. XVIII Encontro Nacional de Geografia, 24 a 30 de junho 2916. Disponível em: http://www.eng2016.agb.org.br/resources/anais/7/1467587766_ARQUIVO_ArtigoA GB.pdf. Acesso em: 27 mar. 2020.

FRANCO, C. de P.; TAVARES, K. C.do A. Way to English for Brazilian Learners: língua estrangeira moderna: inglês: Ensino Fundamental II, $6^{\circ}$ Ano, $1^{a}$ ed., São Paulo: Editora Ática, 2017.

JALIL, S. A.; PROCAILO, L. Metodologia de ensino de línguas estrangeiras: Perspectivas e reflexões sobre os métodos, abordagens e o pós-método. III Encontro Sul Brasileiro de Psicopedagogia - PUCPR, 26 -29 de junho de 2009. Disponível em: http://educere.bruc.com.br/arquivo/pdf2009/2044_2145.pdf. Acesso em: 27 mar. 2020.

KAUARK, F. da S.; MANHÃES, F C.; MEDEIROS, C. H. Metodologia de pesquisa: um guia prático. Itabuna: Via Litterarum, 2010.

MARTINS, B. L. Me manda um whats?!: a aprendizagem de inglês como língua adicional por WhatsApp. Dissertação de Mestrado - Programa de PósGraduação em Letras. Universidade Federal de Pelotas. Pelotas, 2017. Disponível em:

http://bdtd.ibict.br/vufind/Record/UFPL_861fe2ed55cc1506b5c95664e49ceb92.

Acesso em: 2 jul. 2020.

MENEZES, E. T. de; SANTOS, T. H. dos. Verbete analfabetismo tecnológico. Dicionário Interativo da Educação Brasileira -Educabrasil. São Paulo: Midiamix, 2001. Disponível em: https://www.educabrasil.com.br/analfabetismo-tecnologico/. Acesso em: 14 maio 2020.

NEVES, J. L.Pesquisa qualitativa:características, usos e possibilidades. In: Caderno de pesquisas em administração - Universidade de São Paulo (USP), $v^{\circ}$ $1, n^{\circ} .3,2^{\circ}$ semestre. São Paulo, 1996.

PRENSKY, M. O papel da tecnologia no ensino e na sala de aula. Conjectura. Caxias do Sul, v. 15, n. 2,201-204, 2010. Disponível em: http://www.ucs.br/etc/revistas/index.php/conjectura/article/viewFile/335/289.Acesso em: 6 fev. 2020.

RAPHAEL, A. L. Greeting' song, disponível em: https://www.youtube.com/watch?v=ijvYOKr7vUQ. Acesso em: 21 abr. 2020.

SENEFONTE, F. H. R.; TALAVERA, M. N. G. O WhatsApp como ferramenta no ensino-aprendizagem de língua inglesa. Revista Entretextos, UEL: Londrina, v. 18, n. 1 sup., p. 241- 264, Dossiê Temático, 2018. Disponível em: http://www.uel.br/revistas/uel/index.php/entretextos/article/download/33971/23839.

Acesso em: 1 jul. 2020.

SILVA, R. S. Greetings and Goodbyes - Saudações e Despedidas, Disponível em: https://www.youtube.com/watch?v=uBA90FUG-Ko\&t=163. Acesso em: 17 abr. 2020.

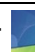


TEIXEIRA, W. B.; FERREIRA, C. J. Do romance ao cinema: tecnologias aplicadas ao ensino de línguas. In: Múltiplos olhares sobre o ensino de línguas tecnologias de informação e comunicação. COELHO, I. M. W. da S.; TEIXEIRA, W. B.; FERREIRA, C. J. (Orgs.). Manaus: EDUA, 2017, p. 19-36.

UNESCO. Organização das Nações Unidas para a Educação, a Ciência e a Cultura. O Futuro da aprendizagem móvel: implicações para planejadores e gestores de políticas. Brasília: UNESCO, 2014.

ZARDINI, A. S. O uso de WhatsApp na sala de aula de Língua Inglesa - relato de experiência em um curso de idiomas. V Simpósio sobre o Livro Didático de Língua Materna e Língua Estrangeira \& do IV Simpósio sobre Materiais e Recursos Didáticos. v. 2. N. 6, abril 2016. Disponível em: http://pdf.blucher.com.br.s3-sa-east-1.amazonaws.com/designproceedings/v-silidiv-simar/021.pdf. Acesso em: 2 de jul. 2020.

O ensino de inglês por meio de tecnologias digitais como complemento das aulas presenciais do ensino fundamental

Recebido: 07/10/19

Aprovado: $27 / 07 / 20$

Como citar: MASSUCATTO, D.; BARROS, L. G. O ensino de inglês por meio de tecnologias digitais como complemento das aulas presenciais do ensino fundamental. Revista de Estudos e Pesquisas sobre Ensino Tecnológico (EDUCITEC), v. 6, e093220, 2020.

Direito autoral: Este artigo está licenciado sob os termos da Licença Creative CommonsAtribuição 4.0 Internacional. 